Available online on 15.9.2018 at http://ujpr.org
Universal Journal of Pharmaceutical Research
An International Peer Reviewed Journal
Open access to Pharmaceutical research

\title{
QUALITY CONTROL ASSESSMENT OF DIFFERENT BRANDS OF CIPROFLOXACIN 500 MG TABLETS IN YEMEN Ali Alyahawi ${ }^{1^{*}}\left(\mathbb{D}\right.$, Abdulmajed Alsaifi $^{2} \mathbb{D}$ \\ ${ }^{I}$ Department of Pharmacy, Al-Razi University, Republic of Yemen. \\ ${ }^{2}$ Department of Chemistry, Sana' a University, Republic of Yemen.
}

\section{ABSTRACT}

Objective: Ciprofloxacin is a fluorinated 4-quinolone or fluoroquinolone antibacterial with a wider spectrum of activity than nalidixic acid and more favorable pharmacokinetics allowing its use in systemic infections. It has been used in the treatment of a wide range of infections. Many different brands and dosage forms of Ciprofloxacin hydrochloride are available in the Sana market that places health practitioners in a dilemma of drug substitution in case of non-availability of a particular brand. The aim of the present study was to evaluate the quality control of five brands of Ciprofloxacin hydrochloride tablets marketed and commonly prescribed in Sana a city. The results and findings of the present study will be interpreted and discussed. Methods: Five brands of Ciprofloxacin hydrochloride tablets $(500 \mathrm{mg}$ ) were purchased from the retail pharmacy outlets and their pharmaceutical quality were assessed by using in-vitro tests as per the British Pharmacopoeia (BP) and unofficial standards as recommended by the manufacturers. The assessment of tablets included the evaluation of uniformity of weight, friability, hardens, disintegration time, dissolution test and assay content by UV spectrophotometric method.

Results: All brands passed USP and BP standards in-vitro quality control tests prescribed for the tablets except hardens test but the all products were satisfactory for hardness.

Conclusion: The results indicated that the overall quality of all tested Ciprofloxacin hydrochloride tablets brands was satisfactory as they met the requirements of the official and unofficial quality control tests.

Keywords: Ciprofloxacin $\mathrm{HCl}$, dissolution, disintegration, friability, hardness, quality control.

Article Info: Received 25 July 2018; Revised 14 August; Accepted 1 September, Available online 15 September 2018

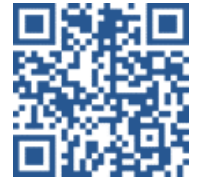
Cite this article-

Ali A, Alsaifi A. Quality control assessment of different brands of ciprofloxacin $500 \mathrm{mg}$ tablets in Yemen. Universal Journal of Pharmaceutical Research 2018; 3(4): 29-33.

DOI: https://doi.org/10.22270/ujpr.v3i4.180

Address for Correspondence:

Dr. Ali Alyahawi, Department of Pharmacy, Faculty of Medical Sciences, Al-Razi University, Republic of Yemen. E-mail: alyahawipharm@yahoo.com

\section{INTRODUCTION}

Ciprofloxacin is a synthetic flouroquinolone derivative with broad spectrum antibacterial activity ${ }^{1}$. It is widely used in the treatment of urinary tract infections, lower respiratory tract infections, bacterial diarrhoea, skin and soft tissue infections, bone and joint infections, gonorrhea, and in surgical prophylaxis ${ }^{2}$. In most of the cases, it would appear that for treatment of above said infections, physicians prescribe ciprofloxacin as a first choice of drug. Ciprofloxacin (CIP) is flouroquinolone with fluorine at position 6 of naphthyridine ring. The chemical structure of ciprofloxacin is shown in Figure $1^{3}$. Quality control is all measures designed to ensure the output of uniform batches of drugs that conform to established specifications of identity, strength, purity, and other characteristics ${ }^{4}$. According to pharmaceutical manufacturers association of U.S. "quality is the sum of all the factors which contribute directly or indirectly to the safety, effectiveness and acceptability of the product" 5 .<smiles>O=C(O)c1cn(C2CC2)c2cc(N3CCNCC3)c(F)cc2c1=O</smiles>

Figure 1: Ciprofloxacin.

Also, quality control is the part of Good Manufacture Practice (GMP) that is concerned with sampling, specifications, testing, documentation and release procedures which ensure that the necessary and relevant tests are actually carried out and that the materials are not released for use, not products released for sale or supply, until their quality has been judged to be satisfactory ${ }^{6}$. A comprehensive evaluation, however, involves the determination of uniformity of weight, 
chemical content, friability, hardness, and disintegration tests along with dissolution rate.

Drugs that are chemically and biopharmaceutically equivalent must be identical in strength, quality, and purity. The content uniformity, disintegration, and dissolution rates must be comparable ${ }^{7}$. The United States Pharmacopoeia describes an HPLC method for CIPRO and CIPRO $\mathrm{HCl}$ assay in bulk, CIPRO injection, ophthalmic ointment, ophthalmic solution and tablets ${ }^{8}$. Despite most methods presented in official compendia are physicochemical assays, these methods do not represent the potency of antimicrobials neither can predict the loss of activity. The aim of the present study is to evaluate the quality of different brands of Ciprofloxacin tablets.

\section{MATERIALS AND METHODS \\ Materials}

Comparative in-vitro quality control parameters between six commercially available tablet different brands of ciprofloxacin were purchased from the retail pharmacies in Sana'a, Yemen. All brands were studied through the evaluation of weight variation, drug content, hardness, friability, disintegration time and dissolution profile. All the tablet brands of ciprofloxacin were labeled to contain $500 \mathrm{mg}$ of ciprofloxacin per tablet and coded as A, B, C, D, and E (Table 1). The study was done by performing various test procedures associated to assess the quality of tablets. USP and British pharmacopoeia were used as standard for the evaluation study.

Table 1: Brands of Ciprofloxacin.

\begin{tabular}{cccc}
\hline $\begin{array}{c}\text { Code } \\
\text { Brand }\end{array}$ & $\begin{array}{c}\text { Country of } \\
\text { origin }\end{array}$ & $\begin{array}{c}\text { Strength } \\
\text { in } \mathbf{~ m g}\end{array}$ & $\begin{array}{c}\text { Batch } \\
\text { number }\end{array}$ \\
\hline A & Yemen & 500 & 12669 \\
B & Yemen & 500 & 13219 \\
C & Yemen & 500 & 1991 \\
D & India & 500 & 1301 \\
E & India & 500 & FD3175 \\
\hline
\end{tabular}

\section{Methodology}

Various analytical methods and tests are important for the development and manufacture of pharmaceutical formulations. The evaluation was done according to USP and BP standards.

\section{Weight Variation}

Twenty (20) tablets from each of the brands were weighed individually using an analytical weighing balance. The average weight for each brand as well as percentage deviations were calculated.

\section{Drug content}

The estimation of drug content for ciprofloxacin tablets was performed by crushing three tablets and quantity equivalent to $45 \mathrm{mg}$ was taken and determined using $0.1 \mathrm{M} \mathrm{HCl}$ using UV spectrophotometer at about 276 $\mathrm{nm}$,

\section{Hardness Test}

A tablet was placed vertically on the Monsanto Hardness tester. The load was then applied along the radial axis of the tablet. The weight or load required for breaking the tablet was noted down. Similarly it was done for 10 tablets.

\section{Friability}

It was performed using Roche Friabilator, 10 tablets were weighed and placed in apparatus. The apparatus was rotated at a speed of $25 \mathrm{rpm}$. The apparatus was made to rotate for $4 \mathrm{~min}$. The tablets were reweighed $\left(\mathrm{W}_{2}\right)$ and compared with their initial weights and percentage friability was obtained. Percentage friability was calculated as:

$$
\text { Percentage friability }=\frac{W 1-W 2}{W 1} \times 100
$$

\section{Disintegration Test}

Six tablets from each brand were employed for this test in a freshly prepared medium, $0.1 \mathrm{~N} \mathrm{HCl}$ at $37^{\circ} \mathrm{C}$ using the BP disintegration apparatus. The disintegration time was taken to be the time no particle remained on the basket of the system.

\section{Dissolution Test}

The dissolution test was carried out using USP apparatus II (paddle method) 5 in 6 replicates for each brand. The dissolution medium was $900 \mathrm{ml} \mathrm{0.1N} \mathrm{HCL}$ which was maintained at $37 \pm 0.5^{\circ} \mathrm{C}$. In all the experiments $5 \mathrm{ml}$ of dissolution sample was withdrawn at $0,10,20$, and $30 \mathrm{~min}$ and replaced with equal volume of dissolution medium to maintain sink condition. The sampling times were selected in due consideration for the short disintegration times. Samples were filtered and assayed by ultraviolet spectrophotometry at $276 \mathrm{~nm}$. The concentration of each sample was determined from a predetermined calibration curve for ciprofloxacin hydrochloride.

Data processing and analysis

After the completion of all test procedures data for all the individual tablets were recorded and separated on a different sheets according to the manufacturer. Finally, data were analyzed by using the above mentioned mathematical formula and MS-Excel®, 2007.

\section{RESULTS AND DISCUSSION \\ General aspect}

The present study was conducted to assess the quality of $500 \mathrm{mg}$ ciprofloxacin tablets marketed in Sana'a Yemen. To achieve this purpose, four different pharmaceutical companies (brands) A, B, C, D, and E were used (Table 1). They were obtained from different retail pharmacies in Sana'a and then were subjected to a number of tests.

Table 2: Average weight, $\%$ deviation from average weight, content uniformity, and \% deviation from content uniformity of different brands of ciprofloxacin tablets.

\begin{tabular}{ccc}
\hline Brands & $\begin{array}{c}\text { Average weight } \\
\text { (mg), \% RSD }\end{array}$ & $\begin{array}{c}\text { Content } \\
\text { uniformity (\%), \% RSD }\end{array}$ \\
\hline A & $679.3 \pm 2.63$ & $98.10 \pm 2.2990$ \\
B & $758.3 \pm 1.07$ & $101.3 \pm 0.897544$ \\
C & $809.6 \pm 1.57$ & $101.34 \pm 3.264$ \\
D & $812.5 \pm 1.70$ & $100.30 \pm 3.607$ \\
E & $842.7 \pm 3.6$ & $101.40 \pm 0.3778$ \\
\hline
\end{tabular}

A quality control study is very important to evaluate tablet properties. Different quality control parameters (e.g., weight variation, drug content uniformity, 
hardens, friability, disintegration time and dissolution tests) were performed to determine the differences among various conventional ciprofloxacin tablets that are available in the Yemeni drug market.

Average Weight and Weight Variation:

Although the uniformity of weight does serve as a pointer to good manufacturing practice (GMP) as well as amount of the active pharmaceutical ingredients, especially for reproducibility of the product which is very essential for mass production of any product. The average weight and weight variation of the different brands of ciprofloxacin tablets tested are shown in Tables 3 and Figure 3. It was found that the average weight of different five brands tablets of ciprofloxacin tablets ranged from $679.3 \mathrm{mg} \pm 2.63 \%$ (A brand) to $842.7 \mathrm{mg} \pm 3.58 \%$ (E brand), while the deviation from average weight for all product is not more than $3.58 \%$. Therefore, all the five brands tested in this study complied with the compendia specification for uniformity of weight which states that for tablets weighing more than $324 \mathrm{mg}$, weight of not more than 2 tablets should not differ from the average weight by more than $5 \%$. Thus, all brands passed the weight uniformity test set by USP. Also, the results indicate the use of different excipients with different weights.

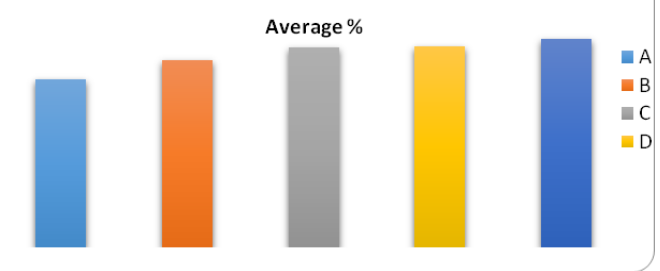

Figure 2: Comparison of different brands weight variation of different brands of ciprofloxacin tablets.

Table 3: Hardness $\left(\mathrm{Kg} / \mathrm{cm}^{2}\right), \%$ deviation from hardness, friability percent $(\%)$, disintegration time (min), dissolution ( $30 \mathrm{~min}), \%$ deviation from dissolution of different brands of ciprofloxacin tablets.

\begin{tabular}{lllll}
\hline Brands & $\begin{array}{l}\text { Hardness }\left(\mathbf{K g} / \mathbf{c m}^{\mathbf{2}}\right) \\
\text { \% RSD }\end{array}$ & $\begin{array}{l}\text { Friability } \\
(\boldsymbol{\%})\end{array}$ & $\begin{array}{l}\text { Disintegration } \\
\text { time (min) }\end{array}$ & $\begin{array}{l}\text { Dissolution (30 min), } \\
\text { \% RSD }\end{array}$ \\
\hline $\mathrm{A}$ & $20.03 \pm 14.397$ & 0.36 & 1.41 & $99.33 \pm 2.03711$ \\
$\mathrm{~B}$ & $27.41 \pm 7.98681$ & 0.37 & 3.16 & $100.15 \pm 1.4314$ \\
$\mathrm{C}$ & $25.585 \pm 8.3994$ & 0.12 & 3.51 & $98.15 \pm 1.796$ \\
$\mathrm{D}$ & $23.35 \pm 8.16783$ & 0.013 & 1.41 & $96.4 \pm 1.16786$ \\
$\mathrm{E}$ & $31.535 \pm 7.37343$ & 0.06 & 4.15 & $98.00 \pm 1.2712$ \\
\hline
\end{tabular}

\section{Content Uniformity (Assay)}

Every unit of tablet should contain the amount of drug substance equivalent to its label amount. For the evaluation of content, assay should be performed. The weight variation test is simplified and alternative to content uniformity test to assure therapeutic utility ${ }^{10}$ and is an indicator of variations in the drug content ${ }^{11}$. The average chemical content (assay) values of the different brands of ciprofloxacin tablets tested shown in Table 2 and Figure 3. The results of the assay of chemical content of ciprofloxacin tablets showed that the active content of all the brands were between $98.10 \pm 2.2990 \%$ (A brand) and $101.40 \pm 0.3778 \%$ (E brand) of the labeled amount specified for ciprofloxacin tablets. A and B brands were chemically equivalent because they had chemical content not less than $90 \%$ and not more than $100 \%(\mathrm{w} / \mathrm{w})^{12}$.

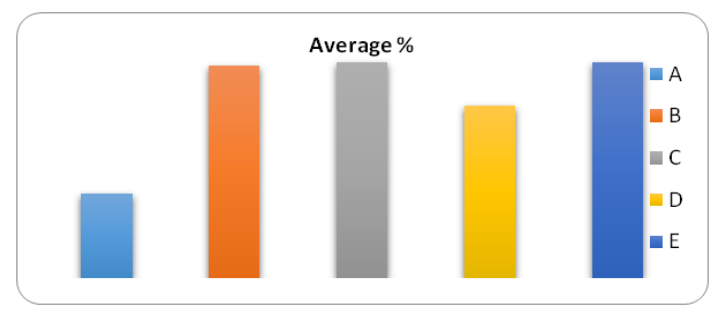

Figure 3: Comparison of assay content (Percent \%) of different brands of ciprofloxacin tablets.
According to the United State Pharmacopoeia ${ }^{13}$, ciprofloxacin tablets should contain not less than $90 \%$ and not more than $110 \%$ of ciprofloxacin tablets. The results indicated that although different manufacturer formulates the different brands are under the BP/USP specification $^{14}$. Furthermore, all the brands of the tablets passed the test for the content of ciprofloxacin tablets. All these brands fall within the British Pharmacopoeia Specification of $95 \%-105 \%{ }^{15}$.

Hardness Test

The crushing strength of the tablets is an essential criterion in the determination of the ability of the tablets to resist chipping, abrasion or breakage under conditions of storage, transportation and handling before storage ${ }^{\mathbf{1 6}}$. Hardness, which is now more appropriately called crushing strength of the tablet is determined to make adjustments to the pressure in the tablet press ${ }^{17}$. It can also influence other parameters such as friability and disintegration ${ }^{18}$.

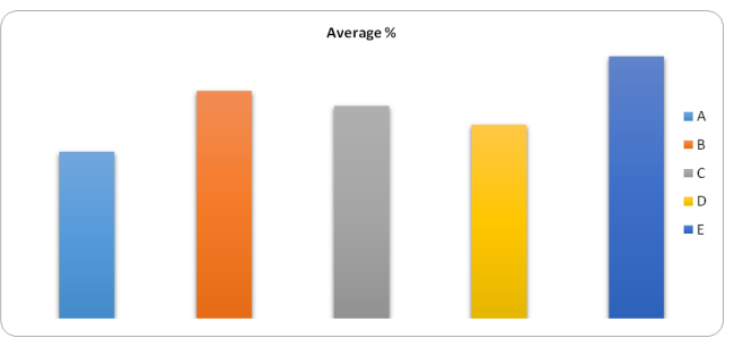

Figure 4: Comparison of hardness of different brands of ciprofloxacin tablets. 
The average values of hardness of the different brands of ciprofloxacin tablets tested shown in Table 3 and Figure 4. Average hardness was found in the range of $20.03 \mathrm{Kg} / \mathrm{cm}^{2}$ (A brand) to $31.535 \mathrm{Kg} / \mathrm{cm}^{2}$ (E brand). The results indicated that all brands of ciprofloxacin tablets were not in the limit range of between 4 to 10 $\mathrm{Kg} / \mathrm{cm}^{2}$ stated $^{17,19}$. Where all brands were greater than $20 \mathrm{Kg} / \mathrm{cm}^{2}$. The hardness of the tablets showed that all brands gave the highest crushing strength. Hardness is referred to as non-compendial test. The hardness or crushing strength assesses the ability of tablets to withstand handling without fracturing or chipping. It can also influence other parameters such as friability and disintegration. Normally, a force of about $4 \mathrm{Kgs}$ is the minimum requirement for satisfactory tablets ${ }^{20}$. Therefore, the tablets of all products were satisfactory for hardness.

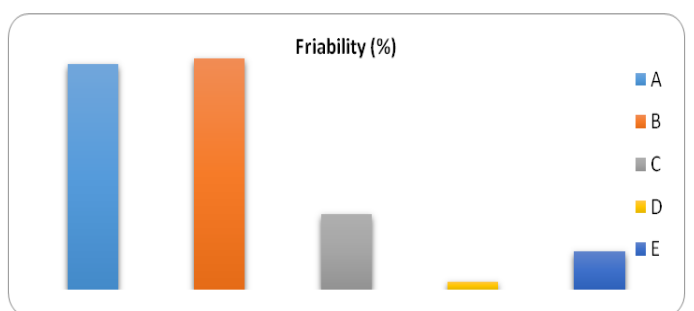

Figure 5: Comparison of friability percent $(\%)$ for different brands of ciprofloxacin tablets.

\section{Friability Test}

Tablet hardness is not the absolute indicator of the tablet strength since some formulations when compressed to very hard tablet tend to cap or laminate on attrition losing their crown part. Therefore, another measure of the tablet strength, its friability is often measured. The loss due to abrasion is a measure of the tablet friability. The average values of friability of the different brands of ciprofloxacin tablets tested shown in Table 3 and Figure 5. The average values of friability ranging from $0.01 \%$ (D brand) to $0.37 \%$ (B brand). The friability was less than $0.5 \%$, indicating that it is within the compendia limits, which showed that the tablets possess good mechanical strength. Also, this showed that all the brands could withstand abrasion without loss of tablet integrity, and the causes of high friability were taken in consideration during manufacturing the tablet. Namely tablets compressed with larger force tend to have slightly lower friability compared with the ones compressed with smaller force $^{21}$.

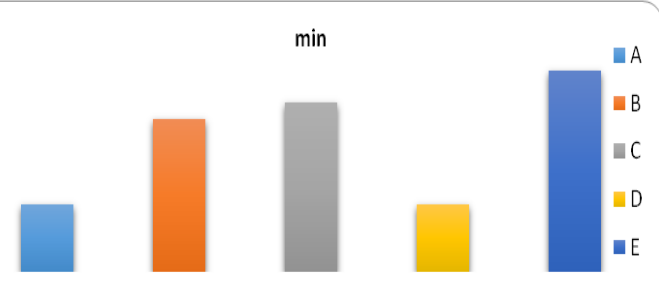

Figure 6: Comparison of disintegration time (min) of different brands of ciprofloxacin tablets.
The pharmacopoeia states that the friability value of tablets should be less than $1 \%$ and as such all the brands of ciprofloxacin had passed this friability specification $^{20}$.

\section{Disintegration Time}

Tablet disintegration time is one of the very important physicochemical properties in solid dosage forms. The disintegration test measures the time required for tablets to disintegrate into particles. This is a necessary condition for dissolution and could be the ratedetermining step in the process of drug absorption. The average values of disintegration of the different brands of ciprofloxacin tablets tested shown in Table 3 and in Figure 6. The results of disintegration time (min) of ciprofloxacin tablets were ranging from $1.41 \mathrm{~min}$ (A and $\mathrm{D}$ brans) to $4.15 \mathrm{~min}$ (E brand). All brands of the ciprofloxacin tablets passed the pharmacopoeia ${ }^{22}$ standard which stipulates a disintegration time of not more than 15 minutes for uncoated tablets, while USP specification for disintegration is $30 \mathrm{~min}$ both for uncoated and film coated tablets. All the brands were complied with the both BP and USP specifications. All the brands were complied with the both BP and USP specifications. The rapid disintegration time exhibited by all the brands might be due to type and amount of disintegrant used in the formulation. All the disintegration times had fallen within the acceptable range.

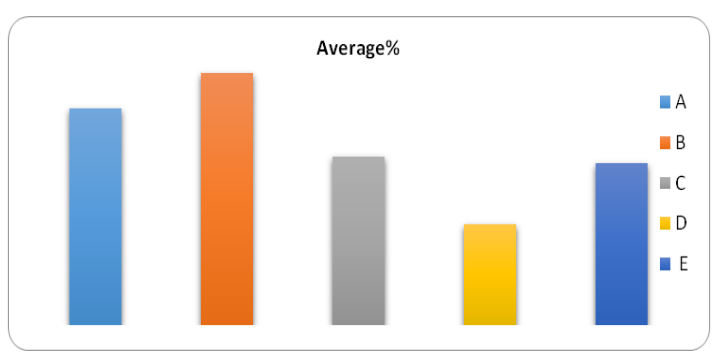

Figure 7: Comparison of dissolution test of different brands ciprofloxacin tablets.

\section{Dissolution Test}

The process of dissolution plays a vital role in liberation a drug from its dosage form and making it available for subsequent gastrointestinal absorption. So, dissolution analysis of pharmaceutical solid dosage forms is a very important test of product quality and it can be used as a sensitive method for differentiating between formulations of same therapeutic agent ${ }^{23-24}$. Drugs with poor dissolution profile will not be available in the body system to elicit therapeutic effect $^{25}$. Also, the dissolution study was carried out to determine the resistance of the materials the acidic environment of the stomach and their suitability as enteric coating materials. The drug release study is a measure of the amount of the drug released into the dissolution medium with time. This study gives an idea of amount of drug available for absorption after oral administration. Drugs with poor dissolution profile will not be available in the body system to elicit therapeutic effect $^{25}$. The average values of dissolution of the different brands of ciprofloxacin tablets tested shown in Table 3 and graphically in Figure 7. The obtained 
dissolution content at 30 minutes was found to be ranged from $96.48 \pm 1.168 \%$ to $100.15 \pm 1.4314 \%$. All brands of ciprofloxacin tablets showed more than $90 \%$ drug release after 30 minutes. At 30 mins, all the brands released more than the pharmacopoeia (USP 30, NF 25) requirement of $70 \%$ active pharmaceutical ingredient ${ }^{20}$. All the brands of the ciprofloxacin hydrochloride tablets complied with the official specification for content uniformity having between $92-104 \%$ as stipulated by the USP. This might be as a result of strict adherence to good manufacturing practice in the process of manufacturing these tablets.

\section{CONCLUSION}

From the present study, it was clearly demonstrated that all five brands of the ciprofloxacin hydrochloride tablet comply with BP and USP specifications for in vitro quality control tests of uniformity of weight, uniformity of content, friability, disintegration time, and dissolution except hardens test for five brands. The USP and BP specification of maximum hardens value of $10 \mathrm{Kg} / \mathrm{cm}^{2}$, where the lower value of hardens is $20.03 \mathrm{Kg} / \mathrm{cm}^{2}$ and the value is $31.535 \mathrm{Kg} / \mathrm{cm}^{2}$. But Hardness is referred to as non-compendial test. Finally, bioequivalence studies are essential and important. Also such studies may be more important in developing countries where counterfeit and substandard drugs have become a major challenge to health care services.

\section{AUTHOR'S CONTRIBUTION}

The manuscript was carried out, written, and approved in collaboration with all authors.

\section{ACKNOWLEDGEMENTS}

The authors extend their thanks and appreciation to the Al-Razi University, Republic of Yemen to provide necessary facilities for this work.

\section{CONFLICT OF INTEREST}

The authors declare that they have no competing interests.

\section{REFERENCES}

1. Tripathy KD: Sulfonamides, cotrimoxazole and qunolones, In: Essentials of Medical Pharmacology. Jaypee Brothers Medical Publishers (P) Ltd, New Delhi, India. 2003; 5: 646652.

2. Hervey SC: Antimicrobial drugs, In: Gennaro AR, Editor, Remington's Pharmaceutical Sciences, Mack Publishing Company, Eston, Pennsylvania 18042.1991; 18: 1163-1241 https://doi.org/10.4103/0019-5154.62748

3. Qureshi MN, Inayat UR Raahman, Gul Akhtar Marwat. Comparative analysis of Ciprofloxacin in different Pharmaceutical products by High Performance Liquid Chromatography. Sci Tech Dev 2010; 31 (1): 69-73.

4. World Health Organization, Guidelines for developing national drug policies, Geneva, 1988

5. Verpoorte R, Mukherjee PK. GMP for botanicals: regulatory and quality issues on phytomedicines. Business Horizons $2003 ; 1: 60$.
6. World Health Organization and Cairo University, Guidelines for good manufacturing practice of pharmaceuticals in Egypt, Faculty of pharmacy, Cairo University, Central administration of pharmacy, WHO, Cairo, 1994. https://doi.org/10.4103/0975-7406.154424

7. Dressman JB, Amidon GL, Reppas C, Shah VP. Dissolution testing as a prognostic tool for oral drug absorption: immediate release dosage forms. Pharm Res 1998; 15(1): 11-22. https://doi.org/10.1023/A:1011984216775

8. The US Pharmacopeia, 30 editions, The US Pharmacopeial Convention, Rockville, 2007.

9. Ngwuluk NC, lawal K, Olorunfemi PO, Ochekpe NA. Postmarket in vitro bioequivalence study of six brands of ciprofloxacin tablets/caplets. Sci. Res. Essay 2009; 4: 298305.

10. Lachman L, Liberman H, Kanig J. The Theory and Practice of Industrial Pharmacy; Third Edition: 293-345, 346-373.

11. Aulton M. Pharmaceutics: The Science of Dosage Form Design. International Student Edition: 304-321, 347-668.

12. The United States Pharmacopoeial Convention, United States Pharmacopoeia 30. Acetaminophen. The United States Pharmacopoeial Convention, Rockville. USA, 2006.

13. Bradoo R, Shahani S, Deewan B, Sudarshan S. Fast dissolving drug delivery system. J Am Med Assoc India 2001; 4 (10): 27-31. https://doi.org/10.4103/2231-4040.90877

14. Willard-Hobart H, Merritt Jr Lynne L, Dean John A (1974) Instrumental Methods of Analysis. ( $5^{\text {th }}$ edn), Von Nostrand, University of Michigan.

15. Milton AS, Wendlandt SA. Possible role for prostaglandin E1 as a modulator of temperature regulation in the central nervous system of the cat. J Physiol 1970; 207:76-7. PMID: 4995176

16. Davidson AG. Ultraviolet-visible absorption spectrophotometry. In Beckett AH, Stenlake JB, (4 ${ }^{\text {th }}$ edn), Practical Pharmaceutical chemistry. CBS Publishers and distributors, New Delhi. 2002; 275-278.

17. Rawlins EA. Bentley's text book of pharmaceutics, Bailliere Tindal publisher, 1977; $8^{\text {th }}$ ed., 289-290.

18. Tanjinatus SO, Md. Ahsanul Haque, Irin Dewan, Islam A comparative in vitro dissolution study of some ciprofloxacin generic tablets under bio waiver conditions by RP-HPLC. Int J Pharm Sci Res 2011; 2(12): 3129-3135

19. Ali HM, Homeida MMA, Ford J, Truman CA, Roberts CJC, Badwan AA. Int J Pharm 1988; 42:155-159.

20. The United State Pharmacopoeia. USP 30 - NF25, the official compendia of standards 2007, 1755-1759.

21. Perioli L, Ambrogi V, Angelici F, Ricci M, Giovagnoli S, Development of Mucoadhesive Patches for Buccal Administration of Ibuprofen. J Con Rel 2004; 99: 73-82. https://doi.org/10.1016/j.jconrel.2004.06.005

22. British Pharmacopoeia. Her majesty's Stationery office, University Press Cambridge. 2002, Vol. 1 and 2.

23. Hsu H, Ayres JW. Chlorpheniramine dissolution and relative urinary exerction from commercial products. J Pharm Sci 1989; 78(10): 844-47. https://doi.org/10.1002/jps.2600781013

24. Bruntion LL. The pharmacological Basis of Therapeutics. Gilman AG, Ra TW, Nies AS and Taylor P (ed), pergamon press. Singapore, Edition 8. 1991: 926-928. https://doi.org/10.1021/jm020026w

25. Giri TK, Parveen N, Thakur D, Alexander A, Badwaik AH, Tripathi DK. In vitro Evaluation of Commercially Available Enteric Coated Tablet Containing Diclofenac Sodium. Int J Res Pharm Biomed Sci 2012; 3 (2):875 - 881. 